\title{
Glomerular lesions in acute tubular necrosis
}

\author{
S. Paul Handa \\ M.B. \\ Department of Pathology, Hartford Hospital, Hartford, Connecticut*
}

\begin{abstract}
Summary
Infraglomerular epithelial reflux has been described as an early microscopic lesion in the kidney of patients with acute renal failure. In our series of forty-four cases of acute tubular necrosis none showed this finding; however, in two cases lesions remotely similar to infraglomerular epithelial reflux and often known as 'glomerular masses' were present. No significance can be attached to these lesions.
\end{abstract}

\section{Introduction}

'Infraglomerular epithelial reflux' is a term used to describe a lesion that has been observed as an early finding in acute renal failure. It consists of desquamation and protrusion of epithelial cells from the proximal tubules into Bowman's space. These cells have pyknotic nuclei and eosinophilic cytoplasm and are seen in the form of epithelial clumps (Fig. 1). Sometimes epithelial cells which look like proximal tubular epithelial cells may be found lining Bowman's capsule and are called 'glomerular masses'. Whether the latter phenomenon is related to the reflux lesion is not completely established. In experimental studies both these lesions have been observed in animals treated with various nephrotoxic drugs (Welch, 1886; Herring, 1900; Waugh \& Beschal, 1961). Similar lesions have also been noted in human subjects dying of acute oliguria and terminal hypotension (Councilman, 1897; Bywaters \& Dible, 1942; Waugh, Schlieter \& James, 1964).

The present communication describes results of a search for these lesions in a series of forty-four necropsied cases of acute tubular necrosis. The historical background and probable pathogenesis of the lesions are also briefly reviewed.

\section{Pathological material}

Forty-four cases of acute tubular necrosis encountered at Hartford Hospital in the 17 years between 1947 and 1963 were reviewed, and a search for the lesion of infraglomerular epithelial reflux in the kidney microsections was made. In only three cases

* Reprint requests to Department of Medicine, Saint John General Hospital, Saint John, New Brunswick, Canada.

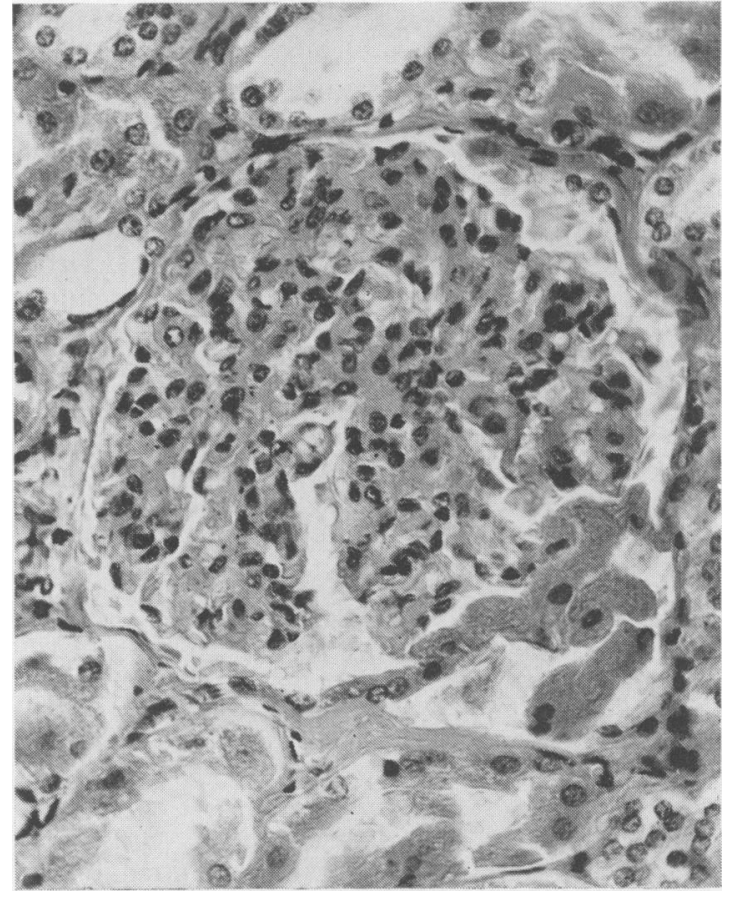

FIG. 1. The typical lesion of inf ${ }_{\wedge}$ aglomerulźr epithelial reflux.

were glomerular lesions of some significance identified. One of them was a case of chronic glomerulonephritis with associated tubular necrosis. In the other two (see below) lesions of glomerular masses associated with acute tubular necrosis were seen. In none of these forty-four cases was the characteristic lesion of infraglomerular epithelial reflux found. However, pathological changes associated with acute tubular necrosis were observed in every case, and the clinical and pathological data of these patients have been presented in a separate publication (Handa \& Lazor, 1966). Of these forty-four patients five died of acute renal failure within the first 2 days, but only one, described below, showed epithelial cells similar to tubular epithelium in 
Bowman's space. In all cases necropsy was done from 1 to $6 \mathrm{hr}$ after death.

Brief accounts of clinical and pathological findings in two cases with lesions of glomerular masses are presented below.

\section{Case 1}

A 41-year-old white man was admitted on 23 April, 1949, in a comatose state. He had been a known alcoholic for 6 years, and he had been consuming excessive amounts of alcohol before the present illness.

On admission he was obese and markedly jaundiced. The blood pressure was $110 / 50 \mathrm{~mm} \mathrm{Hg}$, the pulse $116 / \mathrm{min}$ and temperature $100^{\circ} \mathrm{F}$. A few telangiectatic lesions were present on the chest wall. There were moist rales at the lung bases. The liver was palpated $10 \mathrm{~cm}$ below the right costal margin, and massive ascites was present. The blood nonprotein nitrogen level was $240 \mathrm{mg} / 100 \mathrm{ml}$. Urine specific gravity was 1010 , and microscopic examination showed a few red blood cells and leucocytes. The urinary output was too small to measure. Intravenous fluids were begun but he died $14 \mathrm{hr}$ after admission.

Necropsy was performed $1 \mathrm{hr}$ after death. The heart was hypertrophied. The liver weighed $3120 \mathrm{~g}$ and was bright yellow. Each kidney weighed $280 \mathrm{~g}$. The surfaces of the kidneys were smooth and yellow. On microscopic examination yellowish-brown pigment was present in the renal tubules. The tubular cells were irregularly enlarged and in many places had sloughed from the basement membrane. Tubular epithelial cells were noted in capsular spaces in a few fields.

\section{Case 2}

A 41-year-old white man was admitted on 23 June, 1961, complaining of excruciating left anterior chest pain after sustaining multiple injuries in an automobile accident.

On admission. He was in a state of shock, with a blood pressure of $70 / ? \mathrm{mmHg}$, and his temperature was $97^{\circ} \mathrm{F}$. There were no external injuries, but the seventh, eighth and ninth left ribs were fractured. Bowel sounds were absent. An exploratory laparotomy on the same day revealed a lacerated pancreas and retroperitoneal and intra-abdominal hemorrhage. The post-operative period was complicated by marged oliguria; the urinary output ranged from 28 to $460 \mathrm{ml} /$ day until $15 \mathrm{July}$ when it increased to $2500 \mathrm{ml}$. The patient subsequently developed staphlococcal septicemia and died 26 days after admission.

Necropsy performed $2 \mathrm{hr}$ after death. The pancreas was markedly necrotic. There was an old thrombosis of the right renal artery and a massive right renal infarction. The right kidney weighed $125 \mathrm{~g}$ and the left $240 \mathrm{~g}$. The superior mesenteric artery and the portal vein were occluded by blood clots. Widespread peritonitis and a subhepatic abscess were also noted. Microscopic examination of the left kidney revealed a typical picture of acute tubular necrosis, and Bowman's capsule was lined by tubular epithelium. A few epithelial cells along with proteinaceous material were seen free in the capsular spaces (Fig. 2). The right kidney was completely necrotic.

\section{Discussion}

In 1897 Councilman described infraglomerular epithelial reflux for the first time and demonstrated this lesion in one of the forty-nine cases of nephritis that he reviewed. Occasional reports referring to this lesion appeared in the literature (Welch, 1886; Herring, 1900) until 1961 when Waugh \& Beschal (1961) demonstrated the evolution of this lesion at various intervals after the renal failure induced in rats by the administration of serotonin. It is apparent from their study that epithelial protrusions, i.e. epithelial masses, in the capsular spaces come from the tubular lining and that the phenomenon of infraglomerular epithelial reflux has become pronounced by 3-12 hr after the onset of renal failure. Subsequently, Waugh et al. (1964) found these lesions fifteen times in 109 routine autopsies at the hospitals associated with Queen's University, Kingston, Canada. Of these fifteen cases six had clinical features of oliguria or hypotension prior to death.

The lesions commonly seen in acute tubular necrosis fall in two categories, ischemic and nephrotoxic (Oliver, 1953). The tubular epithelium undergoes necrosis in both types, but in the former the basement membrane fragments as well. Whatever the underlying cause may be, the first development is probably the desquamation of the epithelial cells from the upper part of the proximal tubules. These cells are subsequently displaced upward into the capsular space. The latter phenomenon is ascribed to obstruction of the tubular lumen with swollen cells or interstitial edema below the site of the lesion and simultaneous cessation or decrease in glomerular filtration, and presumably would depend upon the available volume in Bowman's space. Further progression of this lesion takes place rapidly. The cellular mass breaks up into eosinophilic debris which is often seen as a proteinaceous precipitate in the capsular spaces. At times the cytoplasm of these cells shows fat-laden vacuoles. The pyknotic nuclei break up into fragments and are seen as basophilic granular material in the tubular lumen.

Brun \& Munck (1957) reviewed kidney biopsies done at variable intervals during the course of renal failure and found no glomerular abnormalities. 


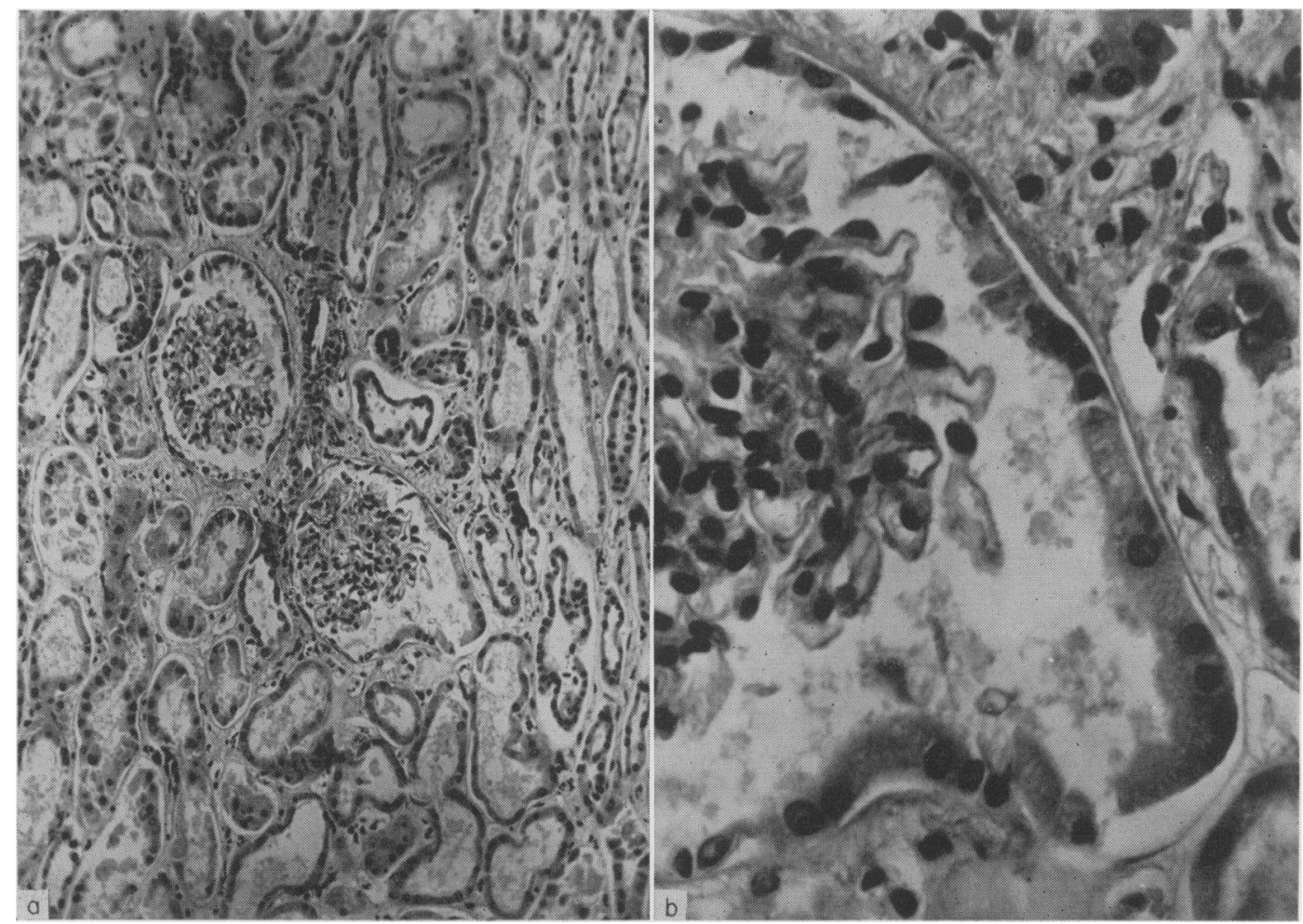

FIG. 2. (a) Tubular epithelium and proteinaceous material seen in the capsular spaces, more so in the infraglomerular region. (b) Magnified view of glomerulotubular junction from (a). Note the dilation of the urinary pole and tubular epithelium with proteinaceous material along the capsule and in the capsular space.

Other authors described changes of hyalinization and periglomerular fibrosis (Sevitt, 1959; Price \& Palmer, 1960) but no mention was made of infraglomerular epithelial reflux. Similarly this finding was noteworthy by its absence in all of our five patients who died after less than 2 days in the oliguric phase of renal failure. As has already been suggested, these lesions are probably transient and are not usually present at the time when biopsied or necropsied tissue is examined. However, the absence of the reflux phenomenon in our series is in contrast to the findings reported by Waugh et al. (1964) in their series of routine autopsies, and hence the clinical application and pathological significance of this finding appears limited.

The lesions of glomerular masses seen in our two cases are similar to the findings demonstrated in the past by Bywaters \& Dible (1942) and Finckh, Jeremy \& Whyte (1962). These lesions have been described as very remotely similar to infraglomerular epithelial reflux. The proteinaceous material in these lesions is ascribed to the breakdown of refluxed tubular epithelium cells, and the proximal epithelial cells found free in and lining Bowman's space are felt to represent an overgrowth of regenerating tubular cells (Waugh, personal communication). These cells are apparently viable, in contrast to the necrotic epithelial cells seen in infraglomerular epithelial reflux. This point suggests that these lesions are different.

In 1942 Bywaters \& Dible analysed the renal lesions seen in cases of traumatic anuria and discussed the origin of epithelial cells in glomerular masses. They postulated that these cellular masses might be due to either metaplasia of capsular lining, or to a direct upward growth of tubular epithelium. The latter phenomenon seems more likely in view of the embryologic development of Bowman's capsule and proximal tubules from a common mesenchymal tissue, and the extension of tubular epithelium along the capsular wall may be an adaptive phenomenon in which the damaged nephron attempts to compensate for the inefficient function of regenerating young epithelial cells in proximal tubules. Opposite conclusions have been reached by other authors (Allen, 1962) who believe that these lesions may be fixation artefacts. The fact that post-mortem autolytic changes are most 
pronounced in the proximal tubules may explain why tubular epithelial cells can be seen in the glomeruli of only some of these patients with acute tubular necrosis.

Glomerular abnormalities in acute tubular necrosis remain vague and inadequately understood.

\section{Acknowledgment}

A grateful acknowledgment is made to Dr Robert Tennant, Director of Pathology, Hartford Hospital, Hartford, Connecticut.

\section{References}

Allen, A.C. (1962) The kidney. Medical and Surgical Diseases, 2nd edn, p. 750. Grune \& Stratton, New York.

Brun, C. \& MuncK, O. (1957) Lesions of the kidney in acute renal failure following shock. Lancet, ii, 603.

Bywaters, E.G.L. \& Dible, J.H. (1942) The renal lesion in traumatic anuria. Journal of Pathology and Bacteriology, 54, 111.

Councilman, W.J. (1897) An anatomical and bacteriological study of 49 cases of acute and subacute nephritis with special reference to glomerular lesions. Medical and Surgical Report. Boston City Hospital, 8, 31.
Finckh, E.S., Jeremy, D. \& Whyte, H.M. (1962) Structural renal damage and its relation to clinical features in acute oliguric renal failure Quarterly Journal of Medicine, 31, 429.

HANDA, S.P. \& LAzor, M.Z. (1966) Acute tubular necrosisa Review of 44 Necropsied cases. American Journal of Medical Science, 251, 29.

Herring, P.T. (1900) The development of the Malpighian bodies of the kidney and its relation to pathological changes which occur in them. Journal of Pathology and Bacteriology, 6, 459 .

OLIVER, J. (1953) Correlation of structure and function and mechanisms of recovery in acute tubular necrosis. American Journal of Medicine, 15, 535.

Price, J.D.E. \& Palmer, R.A. (1960) A functional and morphological follow-up of acute renal failure. Archives of Internal Medicine, 105, 114.

Sevitt, S. (1959) Pathogenesis of traumatic uremia. Revised concept. Lancet, ii, 135.

WAUGH, D. \& BESCHAL, H. (1961) Infra-glomerular epithelial reflux in the evolution of serotinine nephropathy in rats. American Journal of Pathology, 39, 547.

WAugh, D., Schlieter, W. \& JAmes, A.W. (1964) Infraglomerular epithelial reflux. Archives of Pathology, 77, 93.

WELCH, W.H. (1886) An experimental study of glomerulonephritis. Transactions of the Association of American Physicians, 1, 171 (cited in Herring, P.T., 1900). 